\title{
Long-term survival for infants born with orofacial clefts in Western Australia
}

\section{Authors:}

Jane C Bell ${ }^{1}$

Natasha Nassar ${ }^{2}$

Carol Bower ${ }^{3,4}$

Robin M Turner ${ }^{5}$

Camille Raynes-Greenow ${ }^{1}$

\section{Affiliations:}

1. Sydney School of Public Health, University of Sydney, New South Wales

2. Population Perinatal Health Research, Kolling Institute for Medical Research, University of Sydney, New South Wales

3. Western Australian Register of Developmental Anomalies, King Edward Memorial Hospital, Subiaco, Western Australia

4. Telethon Institute for Child Health Research, Centre for Child Health Research, University of Western Australia, Western Australia

5. School of Public Health and Community Medicine, University of New South Wales, New South Wales

\section{Support:}

Ms Bell was supported by the Bob and Nancy Edwards Scholarship, University of Sydney. Assoc Prof Nassar is supported by a National Health and Medical Research Council (NHMRC) Career Development Fellowship (no. 1067066)

Prof Bower is supported by a NHMRC Principal Research Fellowship (no. 634341)

Dr Raynes-Greenow is supported by a NHMRC Career Development Fellowship (no. 1087062)

This study was supported by the Developmental Pathways in WA Children Project [Australian Research Council Linkage Project grant (LP100200507)].

\section{Running title:}

Survival for infants with orofacial clefts

\section{Corresponding author:}

Jane Bell

Room 129A, Edward Ford Building A27

School of Public Health

University of Sydney

NSW 2006

Australia

Ph 61-2-9351 7789

Email: janecbell@gmail.com 


\section{Long-term survival for infants born with orofacial clefts in Western Australia}

\section{Abstract}

Background: Only two population-based studies have reported survival beyond 15 years for individuals with orofacial clefts (OFC), and only for individuals with isolated OFC.

Compared to the general population, long-term survival was similar for individuals with cleft lip only (CLO), lower for individuals with cleft palate only (CPO). Results for those born with isolated cleft lip and cleft palate (CLAP) were inconsistent.

Methods: Using linked population-based health data, including a congenital anomaly register with active surveillance and diagnoses up to six years, we compared survival at one, five and 20 years for infants born 1980-2010 with, and without OFC.

Results: Of the 8112 live born infants in the cohort, 186 died before 20 years; most (81\%) died during infancy. Compared to infants without OFC, infants born with all types of isolated OFC \pm additional minor anomalies had similar infant survival (around 99\%), but we found lower survival for infants with all cleft types and an additional major anomaly (66-84\%). From one to five years, only infants with CPO and an additional major anomaly had lower survival (97\%) compared to children without OFC (99.9\%). From five to 20 years, children with all cleft types, with or without additional major anomalies had similar survival to children without OFC (98-100\%).

Conclusion: Parents with a child diagnosed with an OFC \pm additional minor anomalies only can be reassured that the OFC does not influence survival rates in infancy, or long term. Infant survival was lower only for children with OFC and additional major anomalies.

Key words: cleft lip, cleft palate, medical record linkage, survival, Western Australia 


\section{Introduction}

Orofacial clefts (OFC) are generally not lethal anomalies with neonatal and infant survival more likely to be influenced by the presence of additional congenital anomalies. If the OFC is isolated, survival to one year is similar to infants born without anomalies (98-99\%)(Druschel and others, 1996; Tennant and others, 2010). However, infants born with OFC as well as another anomaly have lower infant survival rates (Druschel and others, 1996; Emanuel and others, 1973; Hujoel and others, 1992; Nembhard and others, 2001). Depending on the type of co-existing anomaly and classification, 30-79\% of live born infants with an OFC survive beyond the first year (Druschel and others, 1996; Hujoel and others, 1992; Nembhard and others, 2001).

Only two population-based studies have reported survival beyond 15 years, and only for individuals with isolated OFC. In these studies, long term survival for individuals with isolated cleft lip only (CLO) was no different to that of the general population, individuals with cleft palate only (CPO) had slightly lower long term survival, and results for those born with isolated cleft lip and cleft palate (CLAP) were inconsistent (similar, or lower than the general population) (Christensen and others, 2004; Tennant and others, 2010). In Australia, Victoria is the only state to have published information on survival beyond birth but only up to 28 days (Vallino-Napoli and others, 2004; Vallino-Napoli and others, 2006). As no information on long term survival for an Australian population with OFC is available, we aimed to describe survival at one year, five, and 20 years for children with OFC compared to children without OFC.

\section{Methods}


We used linked population-based health data from the Western Australian Data Linkage System (WADLS). The WADLS uses computerised probabilistic matching and clerical review to link all records for an individual occurring in over 30 population-based administrative and research health data collections in WA (Holman and others, 2008). In this study we used individuals' records from the WA Register of Developmental Anomalies (WARDA), the Midwives Notification System, birth and death registrations, hospital separations, state-wide school test results and the Intellectual Disability database. Linked data from the WADLS have been validated and used extensively for health research (Holman and others, 2008). The WARDA is a population-based statutory system of congenital anomalies, with multiple sources of active ascertainment of structural and functional anomalies diagnosed up to six years of age. Most minor anomalies are excluded unless they are disfiguring or require treatment (Bower and others, 2012). The Midwives Notification System is a legislated surveillance system covering all births in WA of $>20$ weeks gestation or $400 \mathrm{~g}$ birthweight. The Birth and Death Registries collect data on all births and deaths registered in WA.

Our study population included live born infants from 1980-2010 with OFC identified from the WA Register of Developmental Anomalies (WARDA), using the BPA-ICD9 codes for cleft palate only (CPO) (74900-74909), cleft lip only (CLO) (74910-74919) and for cleft lip and palate (CLAP) (74920-74927, 74929). If other congenital anomalies were recorded as well as OFC, these infants were defined as having an additional anomaly. Children with additional anomalies were further classified as having either only minor anomalies, or having at least one major anomaly. Cases of OFC without other anomalies were defined as isolated. A comparison cohort, frequency matched on year of birth and not diagnosed with OFC, was 
randomly selected from live born infants recorded in the Midwives Notification System. Deaths were identified from death registration data from 1980 to 2012.

Differences in the distribution of characteristics were compared using Chi square tests. We calculated relative survival rates by comparing survival rates (per 100 children) for children with OFC (all, isolated OFC, OFC + only additional minor anomalies and OFC with one or more additional major anomalies) to children without OFC at ages up to one year, from one up to five years, and from five up to 20 years. Denominators for each analysis included children alive at the beginning of the period and with the potential for follow up to that age. For example, all live born children in the cohort were included in the analysis of survival to one year, those born 1980-2007 and alive at one year were included in the analysis for survival from one up to five years, and those born 1980-1992 and alive to five years were eligible for analysis for survival between 5 up to 20 years. As mortality for individuals with OFC is highest in infancy (Christensen and others, 2004; Tennant and others, 2010), and may have changed over time, we compared infant survival for children with each cleft type over three decades (births in the 1980s, 1990s and 2000s) using the Cochran-Armitage Trend Test. Due to violation of the proportional hazards assumption, we could not calculate KaplanMeier curves or conduct survival analyses. As such, we used logistic regression to determine predictors for infant mortality, investigating the effects of OFC type, additional anomalies, infant's sex, term or preterm birth, birthweight, type of delivery, plurality, maternal age, maternal smoking during pregnancy, indigenous status, geographic residence at birth, and year of birth. We conducted statistical analyses using SAS 9.3 (SAS Institute Inc, 2012).

We looked for evidence that children remained resident in WA by examining each individual's records linked to other administrative data, including hospital separations (1980- 
2010), state-wide school test results (1999-2011) and the Intellectual Disability Database (1980-2010) and conducted a sensitivity analysis excluding those with no additional linked records.

The study protocol was approved by the WA Department of Health Human Research Ethics Committee and the WA Aboriginal Health Ethics Committee. These approvals were recognised by the University of Sydney’s Human Research Ethics Committee.

\section{Results}

Our study included 1509 children diagnosed with OFC and 6603 without OFC. Birth characteristics of the cohort are shown in Table 1. Importantly, compared to infants without OFC, infants with OFC were more likely to have birth characteristics associated with poorer survival, especially being born preterm, and with low birthweight. Among children with OFC, children with CLO or CLAP were more likely to be male (62.5\% and $63.3 \%$ respectively), and children with CPO were more likely to be female (56.2\%). The occurrence of additional anomalies varied by cleft type (17\% of infants with CLO, $28 \%$ of those with CLAP and 56\% of infants with CPO) and these differences were statistically significant (P $<0.0001)$. Only $13 \%$ of children with OFC and additional anomalies had only minor anomalies and this did not vary by cleft type $(\mathrm{P}=0.635)$. Only $5.2 \%$ of infants without OFC had an anomaly. Eleven (0.8\%) children with OFC and 1213 (18.6\%) children without OFC had only birth information, and no death registration or other record in the linked datasets.

Of the 8112 live born infants in the cohort, 186 died before 20 years, and most $(n=150$, 80.6\%) died during infancy. At one year, 1396 (92.5\%) infants with OFC were alive, compared to 6566 (99.4\%) of the infants without OFC (relative rate survival 0.93 [95\%CI 
0.92, 0.94]). Seventeen children died between one to five years, and 19 between five to 20 years.

Only 75 children with OFC had additional minor anomalies only and none died before 20 years of age. For this reason we grouped them with the children with isolated OFC and we compared this group of children, and the children with OFC and at least one additional major anomaly to children without OFC. At younger ages, survival varied by OFC type and whether or not the cleft was isolated or occurred with additional major anomalies (Table 2). Infants with each type of cleft were less likely to survive to one year than infants without OFC. However, lower infant survival in infants with OFC was confined to those with an additional major anomaly; infants with isolated OFC \pm minor anomalies had similar survival rates to infants without OFC. For children born in each of the decades from the 1980s to 2000s, infant survival improved for infants born with CLAP, CPO or without OFC, but not for infants with CLO (Table 3).

These results were confirmed by the predictive model (Table 4). The odds of infant mortality for those with additional major anomalies varied by the type of OFC [significant interaction between cleft type and having additional anomalies or not $(\mathrm{P}=0.028)]$. For consistency in comparisons, children with no OFC (with or without anomalies) remained the reference group in this analysis. Infant mortality was not increased for infants with isolated OFC \pm minor anomalies. The odds of infant mortality were 47 and 65 times higher respectively for infants with CLO or CLAP and additional major anomalies compared to infants with no OFC, and 20 times higher for infants with CPO and another major anomaly. Low birthweight and preterm birth were also associated with increased odds of mortality in the first year, and mortality declined with each year of birth after 1980 . 
Survival from one to five years was the same for children with CLO and CLAP with or without co-existing major anomalies as for children without OFC. However, survival remained lower for children with CPO and additional major anomalies (Table 2). From five up to 20 years, children with and without OFC had similar survival rates. The sensitivity analysis, excluding children with only birth records, did not alter survival estimates for any age periods.

\section{Discussion}

This is the first population-based study to report long term survival for children with isolated OFC as well as with co-existing anomalies. Survival was lowest in infancy, but compared to infants without OFC, survival for infants born with OFC in WA was only lower for those born with additional major congenital anomalies. Survival to one year has improved since the 1980s, and was also associated with term rather than preterm birth, and higher birthweight. After infancy, survival for children with OFC was no different from the general childhood population without OFC, except for survival in children with CPO and an additional major anomaly which remained lower from one up to five years.

Infant survival for WA children with OFC was similar to that reported for Canadian children born 1979-86 (Agha and others, 2006) and for infants with each OFC type, with or without additional anomalies from Northern England, Scotland and New York State (Dastgiri and others, 2003; Druschel and others, 1996; Tennant and others, 2010). Survival was slightly higher in our WA data compared to that found in Texas, where additional anomalies were classified as life threatening or not, making a direct comparison difficult (Nembhard and others, 2001). Slight variations in survival between studies are possibly related to differential 
classification, and inclusion or exclusion of information related to additional anomalies (Tennant and others, 2010). The prevalence of additional anomalies occurring with OFC is high in WA, and probably related to the multiple sources of ascertainment, active surveillance, inclusion of minor and major anomalies and diagnoses up to the age of six years. The differences in infant mortality by cleft type for those with additional major anomalies, may reflect the different patterns of additional diagnoses (and their associated differential mortality rates) reported with these cleft types. For example, in WA, 25\% of infants with CLO or CLAP and co-existing anomalies and 16\% of infants with CPO and coexisting anomalies have chromosomal abnormalities (Bell and others, 2013). This difference in distribution of chromosomal anomalies, together with the high neonatal mortality associated with some chromosomal anomalies (Bourke and others, 2005; Nembhard and others, 2001) may be contributing to differences in survival between these groups.

In our study, survival improved over the three decades for children with CLAP and CPO, but not for children with CLO. However, only 15 children with CLO died, making comparisons over time difficult, and contributing to our null finding. Tennant et al (Tennant and others, 2010) also reported an association between year of birth and probability of survival and suggested that medical advances such as surfactant therapy and corticosteroids to prevent respiratory distress, and the prevention of neonatal sepsis, might have contributed to the reduction in infant mortality. Lower infant survival (82-85\%) was reported for children born with CLAP and CPO in Washington in the 1950s and 1960s (Emanuel and others, 1973), but these rates may reflect medical therapies available at the time and may not be comparable to current rates. The increased use of prenatal diagnosis and increased rates of termination of pregnancy for fetal anomaly are also likely to have contributed to improvements in infant survival for infants with OFC and additional anomalies (Bourke and others, 2005). 
In this study, overall survival from birth to 20 years, while lower for those with CLAP and CPO, was largely related to lower infant survival for those with additional major anomalies. Survival to 20 years for children with isolated CLO and CLAP in Northern England was the same as the general population, but individuals with isolated CPO continued to have lower survival, although their survival rates did not change after infancy (Tennant and others, 2010). In Denmark, survival from birth to 55 years was similar to the general population for individuals with isolated CLO, but lower for those with isolated CLAP and CPO. This latter analysis included births from 1943-87 and despite the comprehensive nature of the Danish registration systems, identification of other anomalies and changes in medical care over time may have influenced these results.

Our study, using linked data from 1980, and with OFC status defined using a populationbased congenital anomaly register with active surveillance, enabled us to compare survival rates between those born with OFC and those without. Completeness of registrations of individuals with OFC is estimated to be 100\% (Bower and others, 1990) and with diagnoses up to six years of age, children with all OFC types were included. The quality of our data is high with linkage proportions $>99 \%$ (Holman and others, 2008).

Survival rates may be over-estimated if children migrated out of WA and died interstate. However, migration out of WA is low (around 2.8\% in 2003 and 2004) (Australian Bureau of Statistics, 2014) and is unlikely to have affected rates greatly, and our sensitivity analysis did not alter results. Although $15 \%$ of participants had no records in additional linked datasets, the absence of records may not indicate migration out of WA. Those in the cohort born more recently have had less time to need hospital services, and would not have been old enough for 
the state-wide school tests. State-wide test results were also not available for older members of the cohort.

Parents receiving a prenatal diagnosis of OFC or with an infant born with OFC can be reassured that isolated OFC \pm minor anomalies only does not influence survival rates in infancy, or long term. Infant survival was lower only for children with additional major anomalies. Children with CPO and additional major anomalies continued to have slightly lower survival from one up to five years, but survival beyond five years was no different between children with and without OFC.

\section{Acknowledgements}

We thank the members of CleftPALS WA and the citizens of Western Australia for the use of their administrative data. Thank you also to Alex Godfrey from Data Linkage Branch of the Department of Health, WA for advice regarding data issues and to Edwina Rudy and Jennifer Quick from the WARDA who also provided advice and suggestions.

This study was supported by the Developmental Pathways in WA Children Project [Australian Research Council Linkage Project grant (LP100200507)].

There is no conflict of interest to declare. 


\section{References}

Agha MM, Williams JI, Marrett L, To T, Dodds L. 2006. Determinants of survival in children with congenital abnormalities: a long-term population-based cohort study. Birth Defects Research 76(1):46-54.

Australian Bureau of Statistics. 2014. Australian Demographic Statistics - 3101.0. Canberra: Australian Bureau of Statistics.

Bell JC, Raynes-Greenow C, Bower C, Turner RM, Roberts CL, Nassar N. 2013. Descriptive epidemiology of cleft lip and cleft palate in Western Australia. Birth Defects Research Part A: Clinical and Molecular Teratology 97(2):101-108.

Bourke J, Bower C, Blair E, Charles A, Knuiman M. 2005. The effect of terminations of pregnancy for fetal abnormalities on trends in mortality to one year of age in Western Australia. Paediatric and Perinatal Epidemiology 19(4):284-293.

Bower C, Forbes R, Ryan A, Rudy E. 1990. Validation studies from the Western Australian Congenital Malformations Registry. Community Health Studies 14(3):274-278.

Bower C, Rudy E, Quick J, Rowley A, Watson L, Cosgrove P. 2012. Report of the Western Australian Register of Developmental Anomalies 1980 - 2011. Perth: King Edward Memorial Hospital.

Christensen K, Juel K, Herskind AM, Murray JC. 2004. Long term follow up study of survival associated with cleft lip and palate at birth. BMJ 328(7453):1405.

Dastgiri S, Gilmour WH, Stone DH. 2003. Survival of children born with congenital anomalies. Archives of Disease in Childhood 88(5):391-394.

Druschel CM, Hughes JP, Olsen CL. 1996. First Year-of-Life Mortality Among Infants with Oral Clefts: New York State, 1983-1990. The Cleft Palate-Craniofacial Journal 33(5):400-405.

Emanuel I, Culver BH, Erickson JD, Guthrie B, Schuldberg D. 1973. The further epidemiological differentiation of cleft lip and palate: a population study of clefts in King County, Washington, 1956-1965. Teratology 7(3):271-281.

Holman CDAJ, Bass AJ, Rosman DL, Smith MB, Semmens JB, Glasson EJ, Brook EL, Trutwein B, Rouse IL, Watson CR, de Klerk NH, Stanley FJ. 2008. A decade of data linkage in Western Australia: strategic design, applications and benefits of the WA data linkage system. Aust Health Rev 32(4):766-777.

Hujoel PP, Bollen AM, Mueller BA. 1992. First-year mortality among infants with facial clefts. Cleft Palate Craniofac J 29(5):451-455.

Nembhard WN, Waller DK, Sever LE, Canfield MA. 2001. Patterns of first-year survival among infants with selected congenital anomalies in Texas, 1995-1997. Teratology 64(5):267-275.

SAS Institute Inc. 2012. SAS 9.3 Cary, NC, USA.

Tennant PWG, Pearce MS, Bythell M, Rankin J. 2010. 20-year survival of children born with congenital anomalies: a population-based study. Lancet 375(9715):649-656.

Vallino-Napoli LD, Riley MM, Halliday J. 2004. An epidemiologic study of isolated cleft lip, palate, or both in Victoria, Australia from 1983 to 2000. Cleft Palate Craniofac J 41(2):185-194.

Vallino-Napoli LD, Riley MM, Halliday JL. 2006. An epidemiologic study of orofacial clefts with other birth defects in Victoria, Australia. Cleft Palate Craniofac J 43(5):571-576. 
TABLE 1. Birth characteristics of live born infants in WA 1980-2010, with and without OFC

\begin{tabular}{|c|c|c|c|c|c|}
\hline & \multicolumn{2}{|c|}{ OFC } & \multicolumn{2}{|c|}{ No OFC } & \multirow[b]{2}{*}{$P$ value ${ }^{a}$} \\
\hline & $\mathrm{N}$ & $\%$ & $\mathrm{~N}$ & $\%$ & \\
\hline Male & 816 & 54.1 & 3423 & 51.8 & 0.117 \\
\hline Singleton & 1453 & 96.3 & 6423 & 97.3 & 0.040 \\
\hline Indigenous & 130 & 8.6 & 424 & 6.4 & 0.002 \\
\hline Birthweight & & & & & $<.0001$ \\
\hline$<2500 \mathrm{~g}$ & 205 & 13.6 & 367 & 5.6 & \\
\hline$\geq 2500 \mathrm{~g}$ & 1303 & 86.4 & 6236 & 94.4 & \\
\hline \multicolumn{6}{|l|}{  } \\
\hline$<37$ & 156 & 12.5 & 373 & 6.9 & $<.0001$ \\
\hline$\geq 37$ & 1097 & 87.6 & 5065 & 93.1 & \\
\hline Delivery & & & & & 0.005 \\
\hline Vaginal delivery & 1092 & 72.5 & 5018 & 76.0 & \\
\hline Caesarean section & 414 & 27.4 & 1585 & 24.0 & \\
\hline \multicolumn{6}{|l|}{$\begin{array}{l}\text { Maternal age at infant's } \\
\text { birth (years) }\end{array}$} \\
\hline$<20$ & 88 & 5.8 & 378 & 5.7 & 0.025 \\
\hline $20-34$ & 1184 & 78.5 & 5361 & 81.2 & \\
\hline$\geq 35$ & 237 & 15.7 & 864 & 13.1 & \\
\hline $\begin{array}{l}\text { Maternal smoking during } \\
\text { pregnancy }^{c}\end{array}$ & 147 & 21.6 & 527 & 18.0 & 0.034 \\
\hline $\begin{array}{l}\text { Geographic residence at } \\
\text { birth }\end{array}$ & & & & & 0.831 \\
\hline City & 966 & 68.1 & 4316 & 69.1 & \\
\hline Inner regional & 151 & 10.7 & 678 & 10.8 & \\
\hline Outer regional & 144 & 10.2 & 604 & 9.7 & \\
\hline Remote & 157 & 11.1 & 654 & 10.5 & \\
\hline
\end{tabular}

${ }^{\mathrm{a}} \mathrm{P}$ value for $\chi^{2}$ test for difference in distribution of characteristic

${ }^{\mathrm{b}}$ Available only since 1986

c Available only since 1998

Missing data: birthweight $n=1$, gestational age $n=2$, delivery $n=3$, maternal smoking $n=1$, geographic residence $n=442$ 


\begin{tabular}{|c|c|c|c|c|c|c|c|c|c|c|c|c|c|}
\hline \multirow{3}{*}{$\begin{array}{l}\text { Birth } \\
\text { Years } \\
1980- \\
2010\end{array}$} & \multicolumn{2}{|c|}{$\begin{array}{l}\text { Number of } \\
\text { children }\end{array}$} & \multirow{2}{*}{$\begin{array}{l}\text { Study period for } \\
\text { analysis }\end{array}$} & \multicolumn{3}{|c|}{ CLO } & \multicolumn{3}{|c|}{ CLAP } & \multicolumn{3}{|c|}{$\mathrm{CPO}$} & \multirow{2}{*}{$\begin{array}{c}\text { No OFC } \\
\text { All }\end{array}$} \\
\hline & OFC & No OFC & & All & Isol $^{\mathrm{a}}$ & Maj & All & Isol $^{\mathrm{a}}$ & Maj & All & Isol $^{\mathrm{a}}$ & Maj & \\
\hline & 1509 & 6603 & Live born - <1 year & $95.8^{\mathrm{b}}$ & 99.7 & $72.6^{b}$ & $91.2^{\mathrm{b}}$ & 99.1 & $66.1^{b}$ & $91.7^{b}$ & 99.2 & $84.0^{\mathrm{b}}$ & 99.4 \\
\hline 2007 & 1236 & 5883 & Alive at $1-<5$ years & 100 & 100 & 100 & 99.5 & 100 & 97.1 & $98.4^{\mathrm{b}}$ & 99.7 & $96.9^{\mathrm{b}}$ & 99.9 \\
\hline 1992 & 512 & 2628 & Alive at $5-<20$ years & 100 & 100 & 100 & 99.4 & 99.3 & 100 & 99.1 & 100 & 98.1 & 99.6 \\
\hline 1992 & 585 & 2655 & Live born - <20 years & 97.7 & 100 & 75.0 & $84.5^{b}$ & 98.0 & $52.5^{\mathrm{b}}$ & $83.5^{\mathrm{b}}$ & 97.2 & $73.2^{\mathrm{b}}$ & 98.6 \\
\hline
\end{tabular}

${ }^{\mathrm{a}}$ Isolated OFC group includes children with OFC \pm additional minor anomaly/ies only

${ }^{\mathrm{b}}$ Relative rate survival lower (95\%CI exclude 1) for children with OFC, compared to children without OFC (with or without additional anomaly)

CLO, cleft lip only; CLAP, cleft lip and palate; CPO, cleft palate only; Isol, Isolated cleft or with minor additional anomaly/ies; Maj,

Cleft with additional major anomaly/ies, OFC orofacial cleft 
TABLE 3. Infant survival (\%) for children born in WA from 1980-2010, by cleft type and decade of birth

\begin{tabular}{lcccl}
\hline \multicolumn{5}{c}{ Decade of birth } \\
& $1980 \mathrm{~s}$ & $1990 \mathrm{~s}$ & $2000 \mathrm{~s}$ & $\mathrm{P}^{\mathrm{a}}$ \\
\hline CLO & 97.3 & 95.2 & 95.2 & 0.425 \\
CLAP & 85.1 & 91.5 & 98.0 & $<.0001$ \\
CPO & 86.1 & 89.8 & 96.8 & $<.0001$ \\
No OFC & 98.9 & 99.7 & 99.7 & 0.0004 \\
\hline
\end{tabular}

${ }^{a}$ Cochran-Armitage Trend test 




